\title{
Development and validation of a repharsed phase- HPLC method for simultaneous determination of rosiglitazone and glimepiride in combined dosage forms and human plasma
}

\author{
Nahed M El-Enany ${ }^{1 *}$, Amina A Abdelal ${ }^{1}$, Fathalla F Belal ${ }^{1}$, Yoshinori I Itoh ${ }^{2}$ and Mitsuhiro N Nakamura ${ }^{2}$
}

\begin{abstract}
Background: Rosiglitazone (ROZ) and glimepiride (GLM) are antidiabetic agents used in the treatment of type 2 diabetes mellitus. A survey of the literature reveals that only one spectrophotometric method has been reported for the simultaneous determination of ROS and GLM in pharmaceutical preparations. However the reported method suffers from the low sensitivity, for this reason, our target was to develop a simple sensitive HPLC method for the simultaneous determination of ROZ and GLM in their combined dosage forms and plasma.

Results: A simple reversed phase high performance liquid chromatographic (RP-HPLC) method was developed and validated for the simultaneous determination of Rosiglitazone (ROS) and Glimepiride (GLM) in combined dosage forms and human plasma. The separation was achieved using a $150 \mathrm{~mm} \times 4.6 \mathrm{~mm}$ i.d., $5 \mu \mathrm{m}$ particle size Symmetry ${ }^{\circledR} \mathrm{C} 18$ column. Mobile phase containing a mixture of acetonitrile and $0.02 \mathrm{M}$ phosphate buffer of pH 5 (60: 40, VN) was pumped at a flow rate of $1 \mathrm{~mL} / \mathrm{min}$. UV detection was performed at $235 \mathrm{~nm}$ using nicardipine as an internal standard. The method was validated for accuracy, precision, specificity, linearity, and sensitivity. The developed and validated method was successfully used for quantitative analysis of Avandary|TM tablets. The chromatographic analysis time was approximately 7 min per sample with complete resolution of ROS $\left(t_{R}=3.7\right.$ min.), GLM ( $t_{R}=4.66 \mathrm{~min}$.), and nicardipine $\left(t_{R}, 6.37 \mathrm{~min}\right)$. Validation studieswas performed according to ICH Guidelines revealed that the proposed method is specific, rapid, reliable and reproducible. The calibration plots were linear over the concentration ranges $0.10-25 \mu \mathrm{g} / \mathrm{mL}$ and $0.125-12.5 \mu \mathrm{g} / \mathrm{mL}$ with LOD of $0.04 \mu \mathrm{g} / \mathrm{mL}$ for both compounds and limits of quantification 0.13 and $0.11 \mu \mathrm{g} / \mathrm{mL}$ for ROS and GLM respectively.

Conclusion: The suggested method was successfully applied for the simultaneous analysis of the studied drugs in their co-formulated tablets and human plasma. The mean percentage recoveries in Avandary|TM tablets were $100.88 \pm 1.14$ and $100.31 \pm 1.93$ for ROS and GLM respectively. Statistical comparison of the results with those of the reference method revealed good agreement and proved that there were no significant difference in the accuracy and precision between the two methods respectively. The interference likely to be introduced from some co-administered drugs such as glibenclamide, gliclazide, metformine, pioglitazone and nateglinide was investigated.
\end{abstract}

Keywords: HPLC, rosiglitazone (ROS), glimepiride (GLM), human plasma

\footnotetext{
* Correspondence: nelenany1@yahoo.com

'Department of Analytical Chemistry, Faculty of Pharmacy, University of

Mansoura, Mansoura, 35516, Egypt

Full list of author information is available at the end of the article
} 
<smiles>CN(CCOc1ccc(CC2SC(=O)NC2=O)cc1)c1ccccn1</smiles>

Rosiglitazone (ROS) (A)<smiles>CCC1=C(C)CN(C(=O)NCCc2ccc(S(=O)(=O)NC(=O)NC3CCCCC3)cc2)C1=O</smiles>

Glimepiride (GLM) (B)<smiles>CNCCOC(=O)C1=C(C)NC(C)=C(C(=O)OCc2ccccc2)C1c1cccc([N+](=O)[O-])c1</smiles>

Nicardipine (NIC) (C)

Figure 1 Structural formulae of the studied drugs.

\section{Background}

Rosiglitazone (ROZ), 5-((4-(2-(methyl-2-pyridinylamino) ethoxy)phenyl)methyl)-2,4-thiazolidinedione (Figure 1) is a thiazolidinedione antidiabetic agent used in the treatment of type 2 diabetes mellitus. It exerts its effect through the peroxisome proliferator-activated receptorgamma, which facilitates the expression of genes responsible for glucose and lipid metabolism [1].

Regarding glimepiride (GLM), 3-ethyl-4-methyl- $\mathrm{N}$-(4[N-((1r,4r)-4 methylcyclohexylcarbamoyl)sulfamoyl]phenethyl)-2-oxo-2,5-dihydro-1 $H$-pyrrole-1-carboxamide
(Figure 1) it is a medium-to-long acting sulfonylurea anti-diabetic drug. It is the first of the third-generation sulfonylurea, and is very potent [2].

The two drugs are co-formulated commercial tablets which is used for the treatment of patients with type 2 diabetes:

Literature survey reveals few analytical methods for the determination of rosiglitazone (ROS) in pharmaceutical preparations and biological fluids, including: spectrophotometry [3,4], voltammetry [5] and HPLC [6-8]. 
As for glimepiride, several methods have been published concerning its analysis in formulations and biological fluids $\mathrm{Viz}$; spectrophotometry [9], polarography [10] and HPLC [11-13].

To the best of our knowledge in recent years only one spectrophotometric method has been reported for the simultaneous determination of ROS and GLM in pharmaceutical preparations [14]. However the reported method suffers from the low sensitivity, for this reason, our target was to develop a simple sensitive HPLC method for the simultaneous determination of ROZ and GLM in their combined dosage forms and plasma. Because HPLC methods have been widely used for routine quality-control assessment of drugs, because of their sensitivity, repeatability, and specificity, we have developed a simple and specific RP-HPLC method for simultaneous determination of ROS and GLM in pharmaceutical dosage forms. Because analytical methods must be validated before use by the pharmaceutical industry, the proposed HPLC-UV method was validated in accordance with International Conference on Harmonization (ICH) guidelines [15], by assessing its selectivity, linearity, accuracy, precision, and limits of detection and quantitation.

\section{Experimental}

\section{Instruments}

\section{Chromatographic System and Conditions}

The HPLC system is LC-10A (Shimadzu, Kyoto, Japan) consisted of a pump (LC-10), UV detector (SPD-10AV) and auto-injector (SIL-10 $\mathrm{A}_{\mathrm{XL}}$ ).

Column: Symmetry ${ }^{\circledR}$ C18 $(150 \mathrm{~mm} \times 4.6 \mathrm{~mm}$ i.d., 5 $\mu \mathrm{m}$ particle size), Waters, Ireland. The column hold up value was the first deviation of the base line obtained.

Mobile phase: consists of a mixture of acetonitrile and $0.02 \mathrm{M}$ phosphate buffer of $\mathrm{pH} 5(60: 40, \mathrm{~V} / \mathrm{V})$. The run

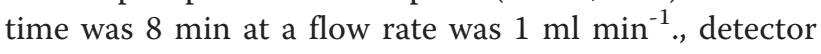
wavelength $235 \mathrm{~nm}$. The injection volume was $30 \mu \mathrm{l}$.

\section{Materials and reagents}

All materials and reagents used were of Analytical Reagent grade.

-Rosiglitazone maleate reference standard was kindly supplied by Glaxo SmithKline, Egypt

- Glimepiride reference standard was kindly supplied by Delta Pharma, Egypt.

-Avandaryl ${ }^{\mathrm{TM}}$ tablets; labeled to contain $4 \mathrm{mg}$ rosiglitazone maleate and $2 \mathrm{mg}$ glimepride per tablet, were purchased from commercial sources in the local market.

-Acetonitrile, methanol, ethanol and propanol (SigmaAldrich, Germany).

-Sodium dihydrogen phosphate and disodium hydrogen phosphate (Winlab, England).
-Human plasma was kindly provided by Mansoura University Hospitals, Mansoura, Egypt and was kept frozen until used after gentle thawing.

\section{Standard solutions}

Stock solutions of ROS, GLM and nicardipine were prepared by dissolving $20 \mathrm{mg}$ of each pure substance in $100 \mathrm{~mL}$ of methanol to obtain a stock solution of $200 \mu \mathrm{g} / \mathrm{mL}$. These stock solutions were further diluted with the same solvent and then with the mobile phase as appropriate to obtain the working standard solution of $0.10-25 \mu \mathrm{g} / \mathrm{mL}$ and $0.125-12.5 \mu \mathrm{g} / \mathrm{mL}$ for ROS, GLM respectively). The solutions were stable for at least three days without alteration when kept in the refrigerator.

General procedures for analysis of laboratory prepared mixture of ROS and GLM

Aliquot volumes containing ROS, GLM and nicardipine (IS) were quantitatively transferred into a series of 10 $\mathrm{mL}$ volumetric flasks, so that the final concentration were in the range of $0.10-25,0.125-12.5$ and $20 \mu \mathrm{g} / \mathrm{mL}$ for ROS, GLM and NIC (IS) respectively. The solutions were completed to the volume with the mobile phase. $30 \mu \mathrm{L}$ aliquots were injected (in triplicate) and the calibration curve was constructed by plotting the peak area ratio against the final concentration of the drug $(\mu \mathrm{g} /$ $\mathrm{mL}$ ). Alternatively the corresponding regression equations were derived.

\section{Application of the proposed method to the analysis of Avandary/ ${ }^{\mathrm{TM}}$ tablets}

Ten Avandaryl ${ }^{\mathrm{TM}}$ tablets were weighed and pulverized well. A weighed quantity of the powder equivalent to $20.0 \mathrm{mg}$ of ROS and $10 \mathrm{mg}$ of GLM were transferred into a small conical flask and extracted three successive times each with $30 \mathrm{~mL}$ of methanol. The extracts were filtered into $100 \mathrm{~mL}$ volumetric flask. The conical flask and filter paper were washed with few milliliters of methanol. The washings were passed into the same volumetric flask, and completed to volume with same solvent. Aliquots covering the working concentration ranges were transferred into $10 \mathrm{ml}$ volumetric flasks. The procedures described under "General procedures" were performed. The nominal contents of the tablets were calculated using the corresponding regression equations.

\section{Application of the proposed method to spiked human plasma}

Blank plasma was spiked with standard solutions of both drugs to achieve the following calibration standard concentrations $0.1-0.25-0.5-0.75$ and $1.0 \mu \mathrm{g} / \mathrm{mL}$; for both of ROS and GLM respectively at constant concentration of NIC $\left(2 \mu \mathrm{g} \mathrm{mL}{ }^{-1}\right)$. 
Aliquots of human plasma $(1 \mathrm{~mL})$ spiked with increasing concentrations of the drugs were transferred into centrifugation tubes. Acetonitrile $(2 \mathrm{ml})$ was added to each tube. After vortex mixing for $5 \mathrm{~min}$., the mixtures were centrifuged at $3500 \mathrm{rpm}$ for $15 \mathrm{~min}$. at room temperature. The Supernatant was evaporated using nitrogen gas in a heating block set at $45^{\circ} \mathrm{C}$. Dried samples were reconstituted with the mobile phase and. Aliquots of $30 \mu \mathrm{L}$ were injected (triplicate) and eluted with the mobile phase under the reported chromatographic conditions. A blank experiment was carried out simultaneously. The peak area ratio was plotted versus the concentration of the drugs in $\mu \mathrm{g} \mathrm{mL}^{-1}$ to get the calibration graph. Alternatively, the regression equations were derived.

\section{Results and Discussion}

After extensive various preliminary experimental trials using different combinations of buffers, organic modifiers (acetonitrile methanol, ethanol and propanol), and after trials using different $\mathrm{C}_{8}$ and $\mathrm{C}_{18}$ reverse pharsedphase (RP) columns, best chromatographic conditions to obtain good separation, resolution and symmetrical peaks for simultaneous determination ROS and GLM were achieved when using a mobile phase mixture of acetonitrile and $0.02 \mathrm{M}$ phosphate buffer of pH 5 (60:
$40, \mathrm{~V} / \mathrm{V})$. The run time was $8 \mathrm{~min}$ at a flow rate was 1 $\mathrm{mL} / \mathrm{min}$. and detector wavelength $235 \mathrm{~nm}$. The injection volume was $30 \mu \mathrm{L}$. Moreover the proposed method allowed the simultaneous determination of ROS and GLM. in their co-formulated tablets and in human plasma. Figure 2 shows a typical chromatogram of mixture of ROS and GLM indicating complete resolution of $\operatorname{ROS}\left(t_{R}=3.7\right.$ min. $)$ and GLM $\left(t_{R}=4.66 \mathrm{~min}\right.$. $)$, and nicardipine $\left(\mathrm{t}_{\mathrm{R}}, 6.37 \mathrm{~min}\right)$.

\section{Chromatographic condition and optimization Choice of column}

Trials were performed using Symmetry ${ }^{\circledR}$ C18 column $(150 \mathrm{~mm} \times 4.6 \mathrm{~mm}$ i.d., $5 \mu \mathrm{m}$ particle size), Waters, Ireland; Zorbax SB-Phenyl column $(250 \mathrm{~mm} \times 4.6 \mathrm{~mm}$ i.d., $5 \mu \mathrm{m}$ particle size), Agilent Technologies, USA, and Hypurity C8 column $(250 \mathrm{~mm} \times 4.6 \mathrm{~mm}$ i.d., $5 \mu \mathrm{m}$ particle size). Thermo Electron Corporation. The experimental studies revealed that the first column was the best one, since it produced symmetrical peaks with high resolution. The phenyl column resulted in separation of both drugs but with low resolution for ROS $\left(t_{R}=3.1\right.$ min.) and GLM $\left(t_{R}=3.69 \mathrm{~min}\right.$.). On the other hand using C8 column resulted in separation of both drugs but with low sensitivity for ROS $\left(t_{R}=3.4 \mathrm{~min}\right.$.) and GLM $\left(t_{R}=4.2 \mathrm{~min}\right.$.

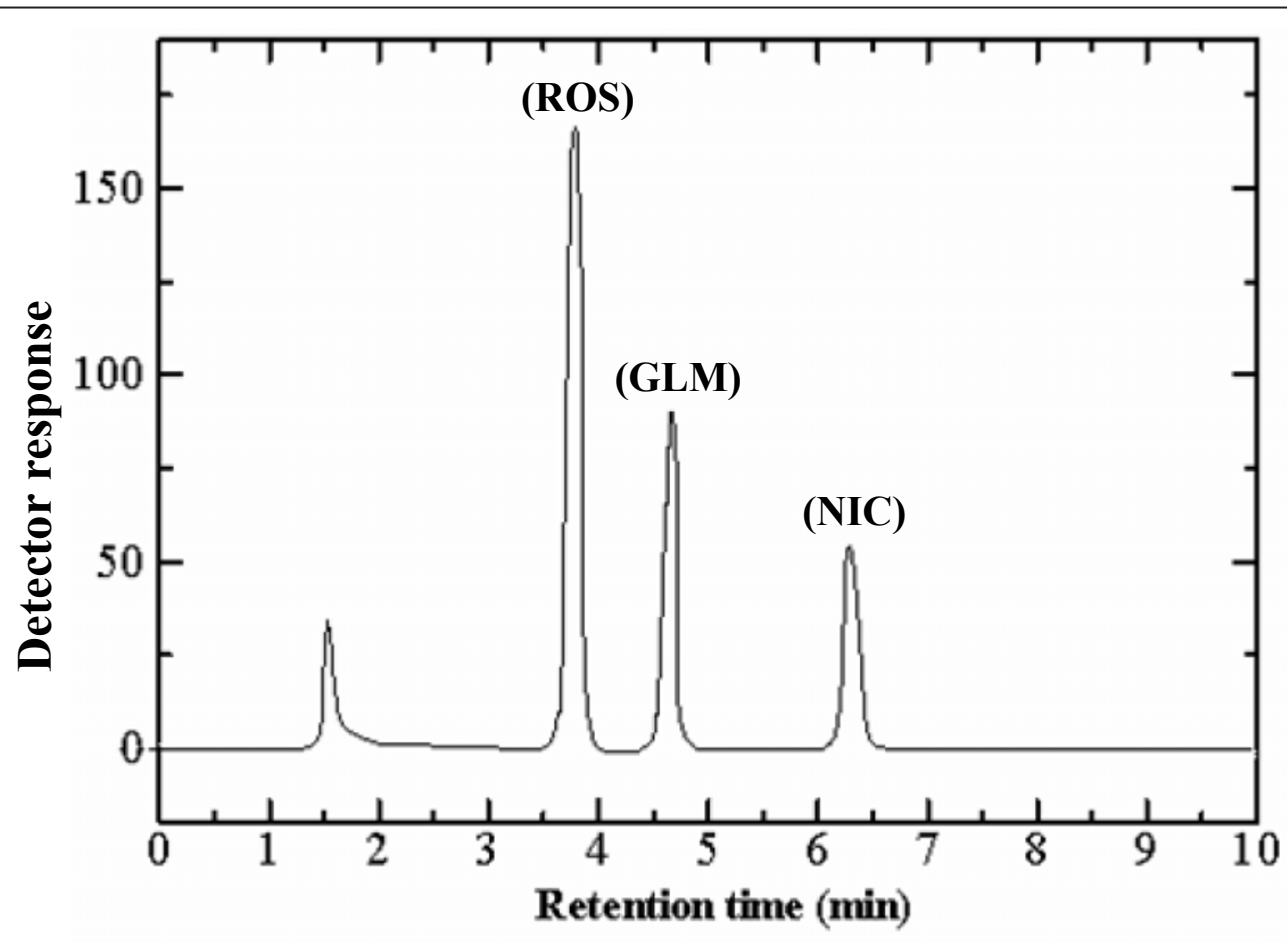

Figure 2 Typical chromatogram of glimepiride $\left(12.5 \mu \mathrm{g} \mathrm{mL}^{-1}\right)$, rosiglitazone $\left(25 \mu \mathrm{g} \mathrm{mL}^{-1}\right)$ and nicardipine $\mathrm{HCl}\left(20 \mu \mathrm{gL} L^{-1}\right) \mathrm{using}$ acetonitrile/0.02 M phosphate buffer of pH 5 (60: 40, V/V) as a mobile phase. 


\section{Mobile phase composition}

Several modifications in the mobile phase composition were performed in order to study the possibilities of improving the performance of the chromatographic system. These modifications included: the type and ratio of the organic modifier, effect of flow rate and the $\mathrm{pH}$

\section{Type of organic modifier}

Acetonitrile was replaced by methanol, ethanol and propanol. Although ethanol and propanol gave sharp peaks, yet they were not selected as using ethanol gave longer retention time and propanol resulted in poor resolution. Methanol on the other hand gave very small and broad peaks. In addition, the three organic modifiers showed low sensitivity. So, acetonitrile was the organic modifier of choice giving symmetrical highly sensitive peaks in a reasonable time.

\section{Ratio of organic modifier}

The effect of changing the ratio of organic modifier on the retention times and resolution of the tested solutes was investigated using mobile phases containing concentrations of $40-70 \%(\mathrm{~V} / \mathrm{V})$ of acetonitrile. It was found that, the retention times of both drugs decreased upon increasing the ratio of acetonitrile up to $70 \%(\mathrm{~V} / \mathrm{V})$. However, the study revealed that the optimum chromatographic separation was achieved upon using $60 \%$ acetonitrile regarding sensitivity and separation within a reasonable time (Figure 3). Although $70 \%$ concentration gave the highest resolution values, yet it was not selected as it resulted in poor separation and non symmetrical peaks.

\section{Effect of $p H$}

As it is well known that the buffer is important during the liquid chromatographic phase because it allows for the separation of organic compounds, $0.02 \mathrm{M}$ phosphate buffer was chosen a buffer as it is very handy with better solubility in organic solvents.

The effect of $\mathrm{pH}$ of the mobile phase on the retention times and the number of theoretical plates for the tested solutes was investigated using mobile phases of $0.02 \mathrm{M}$ phosphate buffer with $\mathrm{pH}$ ranging from 2.6-6.0. It was found that, increasing the $\mathrm{pH}$ would increase the retention time of each of ROS and GLM respectively up to $\mathrm{pH}$ 5.0. Beyond $\mathrm{pH} 5$, the retention time decreased. Figure 4 illustrates that $\mathrm{pH} 5.0$ was the most appropriate one giving well resolved peaks with the highest number of theoretical plates.

\section{Flow rate}

The effect of flow rate on the formation and separation of peaks of the studied compounds was studied and a flow rate of $1 \mathrm{~mL} / \mathrm{min}$. was the optimal for good separation in a reasonable time.

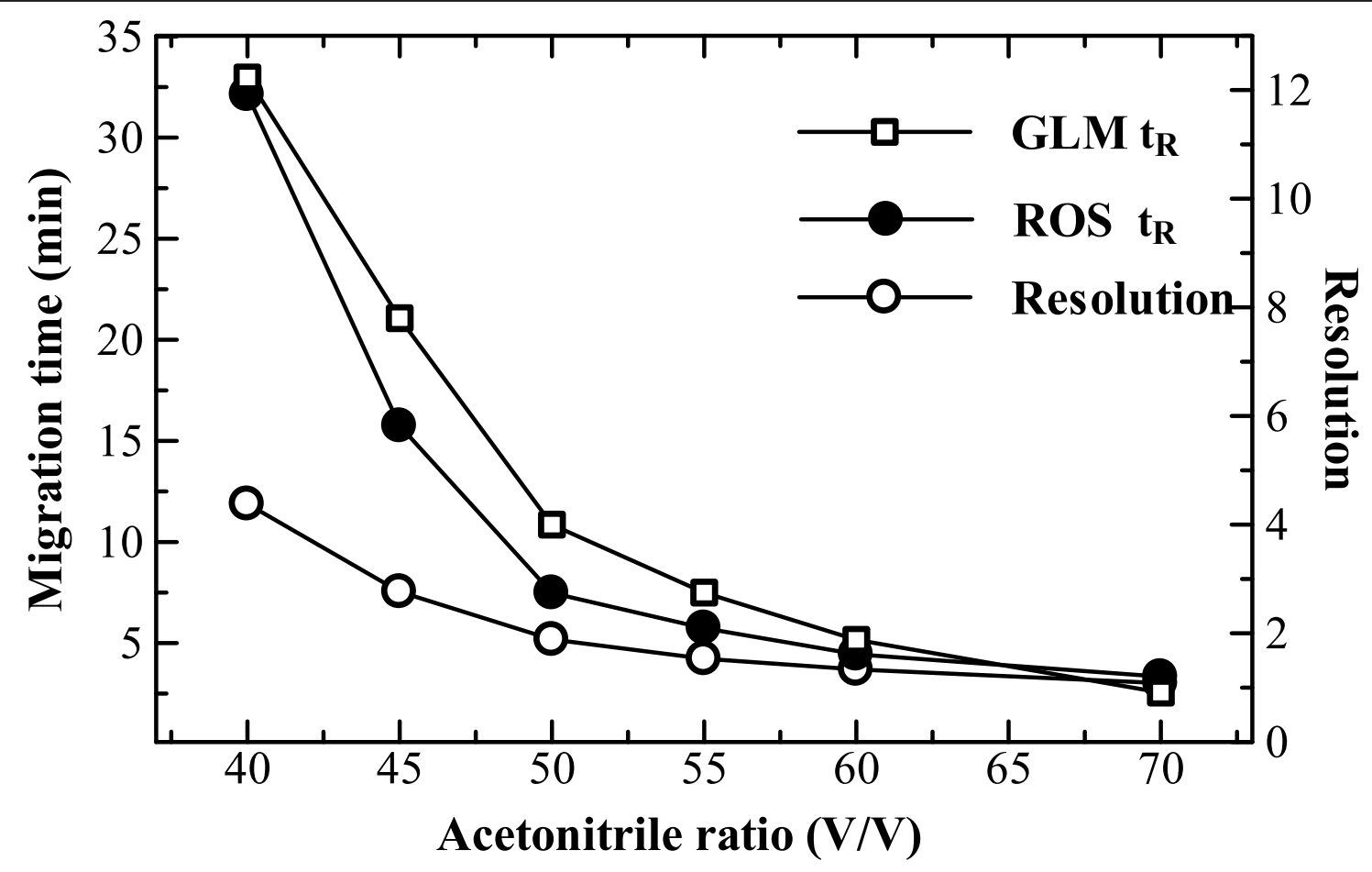

Figure 3 Effect of acetonitrile: phosphate buffer ratio $(\mathrm{pH} 5.0)$ on the resolution of GLM (12.5 $\left.\mu \mathrm{g} \mathrm{mL}^{-1}\right)$ and $\mathrm{ROS}\left(25 \mu \mathrm{gL} \mathrm{L}^{-1}\right)$ using the proposed HPLC method. 


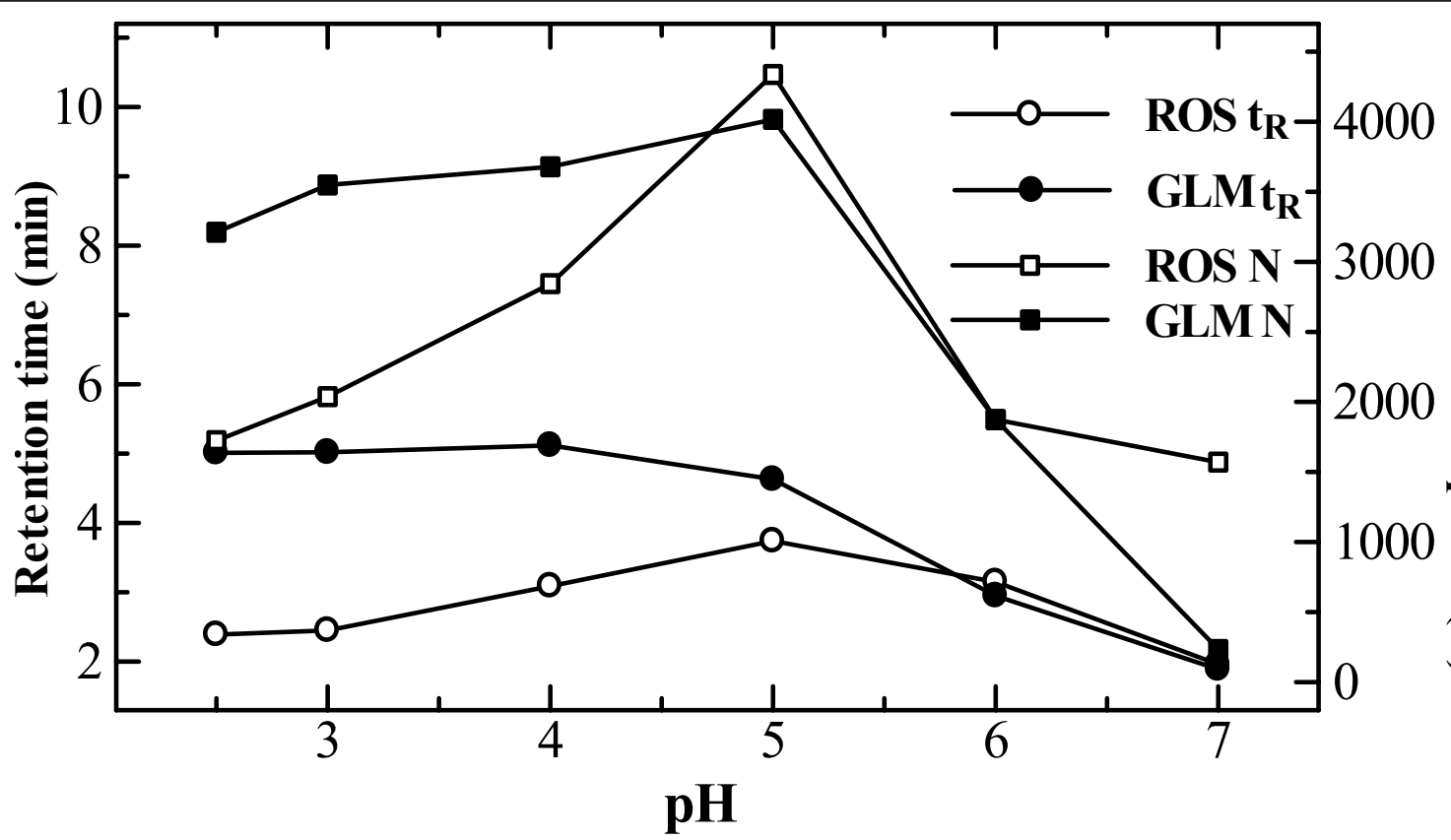

Figure 4 Effect of $\mathrm{pH}$ on the resolution of GLM $\left(12.5 \mu \mathrm{g} \mathrm{mL}^{-1}\right)$ and ROS $\left(25 \mu \mathrm{g} \mathrm{mL}^{-1}\right)$ using the proposed HPLC method.

Validation of the method

\section{Linearity}

Under the above described experimental conditions, a linear relationship was established by plotting the peak area ratio against the drug concentration. The relationship was found to be rectilinear over the range 0.10-25 $\mu \mathrm{g} / \mathrm{mL}$ and $0.125-12.5 \mu \mathrm{g} / \mathrm{mL}$ for ROS and GLM respectively. The results are abridged in Table 1 . Linear regression analysis of the data gave the following equations:

$$
\mathrm{PA}=-5.9 \times 10^{-4}+0.119 \mathrm{C} \quad(\mathrm{r}=0.9999) \text { for ROS }
$$

Table 1 Analytical performance data for the determination of the studied drugs by the proposed method.

\begin{tabular}{ccc}
\hline Parameter & ROS & GLM \\
\hline Linearity range $(\mu \mathrm{g} / \mathrm{mL})$ & $0.10-25$ & $0.125-12.5$ \\
Intercept $(a)$ & $-5.9 \times 10^{-4}$ & $-1.7 \times 10^{-3}$ \\
Slope $(b)$ & 0.119 & 0.122 \\
Correlation coefficient $(r)$ & 0.9999 & 0.9999 \\
S.D. of residuals $\left(\mathrm{S}_{\mathrm{y} / \mathrm{x}}\right)$ & $6.90 \times 10^{-3}$ & $2.68 \times 10^{-3}$ \\
S.D. of intercept $\left(\mathrm{S}_{a}\right)$ & $1.58 \times 10^{-3}$ & $1.39 \times 10^{-3}$ \\
S.D. of slope $\left(\mathrm{S}_{b}\right)$ & $2.88 \times 10^{-4}$ & $2.36 \times 10^{-4}$ \\
Percentage relative standard deviation, \% RSD & 0.80 & 0.92 \\
Percentage relative error, \% Error & 0.28 & 0.35 \\
Limit of detection, LOD $(\mu \mathrm{g} / \mathrm{mL})$ & 0.04 & 0.04 \\
Limit of quantitation, $\mathrm{LOQ}(\mu \mathrm{g} / \mathrm{mL})$ & 0.13 & 0.11 \\
\hline
\end{tabular}

$$
\mathrm{PA}=-1.7 \times 10^{-3}+0.122 \mathrm{C} \quad(\mathrm{r}=0.9999) \text { for GLM }
$$

Where: PA is the peak area ratio, $\mathrm{C}$ is the concentration of the drug in $\mu \mathrm{g} / \mathrm{ml}$ and $\mathrm{r}$ is the correlation coefficient.

Limit of quantitation (LOQ) and limit of detection (LOD)

The limit of quantitation (LOQ) and the limit of detection (LOD) were calculated according to $\mathrm{ICH}$ guidelines (ICH Topic Q2B 2004) [15] using the following equations: [15]

$$
\mathrm{LoQ}=10 \mathrm{~S}_{\mathrm{a}} / \mathrm{b} \text { and } \operatorname{LoD}=3.3 \mathrm{~S}_{\mathrm{a}} / \mathrm{b}
$$

Where $S_{a}$ is the standard deviation of the intercept of the regression lines and $b$ is the slope of the calibration curve.

LoQ values were found to be 0.13 and $0.11 \mu \mathrm{g} / \mathrm{mL}$ for ROS and GLM, respectively, while LoD values were found to $0.04 \mu \mathrm{g} \mathrm{mL}^{-1}$ for both compounds.

Statistical evaluation of the regression lines regarding standard deviation of the residual $\left(\mathrm{S}_{\mathrm{y} / \mathrm{x}}\right)$, standard deviation of the intercept $\left(S_{a}\right)$ and standard deviation of the slope $\left(S_{b}\right)$ is shown in Table 1 . The small values of the figures point out to the low scattering of the points around the calibration curve (Table 1) thus indicating high precision of the method [16].

The proposed method was evaluated by studying the accuracy as percent relative error $(\% \mathrm{Er})$ and precision as percent relative standard deviation (\%RSD). The results are abridged in Table 1. 
Table 2 Assay results for the determination of the studied drugs in their synthetic mixture and co-formulated tablets.

\begin{tabular}{|c|c|c|c|c|c|c|c|c|}
\hline \multirow{2}{*}{$\begin{array}{l}\text { Sample } \\
\text { 1- Synthetic mixture(a) }\end{array}$} & \multicolumn{2}{|c|}{$\begin{array}{c}\text { Concentration taken } \\
(\mu \mathrm{g} / \mathrm{mL})\end{array}$} & \multicolumn{2}{|c|}{$\begin{array}{l}\text { Concentration found } \\
(\mu \mathrm{g} / \mathrm{mL})\end{array}$} & \multicolumn{2}{|c|}{$\%$ Found } & \multicolumn{2}{|c|}{$\begin{array}{c}\text { Reference method } \\
{[14]}\end{array}$} \\
\hline & ROS & GLM & ROS & GLM & ROS & GLM & ROS & GLM \\
\hline & 0.25 & 0.125 & 0.249 & 0.127 & 99.60 & 101.60 & 99.10 & 100.27 \\
\hline & 0.5 & 0.25 & 0.501 & 0.251 & 100.20 & 100.40 & 100.64 & 98.18 \\
\hline & 1.0 & 0.5 & 1.013 & 0.506 & 101.30 & 101.20 & 98.00 & 99.73 \\
\hline & 5.0 & 2.5 & 4.966 & 0.473 & 99.32 & 98.92 & & \\
\hline & 10.0 & 5.0 & 10.005 & 5.014 & 100.05 & 100.28 & & \\
\hline & 15.0 & 7.5 & 15.131 & 7.473 & 100.87 & 99.64 & & \\
\hline & 25.0 & 12.5 & 25.047 & 12.473 & 100.19 & 99.78 & & \\
\hline$X^{\prime}$ & & & & & 100.22 & 100.26 & 99.25 & 99.06 \\
\hline SD & & & & & 0.68 & 0.92 & 1.33 & 1.08 \\
\hline$\%$ RSD & & & & & 0.68 & 0.92 & & \\
\hline $\pm \%$ Error & & & & & 0.26 & 0.35 & & \\
\hline t- test & & & & & 1.58 & 1.80 & & \\
\hline F- test & & & & & 3.83 & 1.37 & & \\
\hline \multirow[t]{4}{*}{ 2-AvandarylTM tablets(b) (4 mg ROS + 2 mg GLM/tablet) } & 0.25 & 0.125 & 0.253 & 0.123 & 101.20 & 98.40 & 98.10 & 101.56 \\
\hline & 1.0 & 0.5 & 0.994 & 0.511 & 99.4 & 102.20 & 99.27 & 98.50 \\
\hline & 5.0 & 2.5 & 5.038 & 2.543 & 100.76 & 101.72 & 100.71 & 100.40 \\
\hline & 10.0 & 5.0 & 10.215 & 4.946 & 102.15 & 98.92 & & \\
\hline$X^{\prime}$ & & & & & 100.88 & 100.31 & 99.36 & 100.15 \\
\hline SD & & & & & 1.14 & 1.93 & 1.31 & 1.54 \\
\hline$\%$ RSD & & & & & 1.14 & 1.93 & & \\
\hline $\pm \%$ Error & & & & & 0.57 & 0.97 & & \\
\hline t- test & & & & & 1.65 & 0.12 & & \\
\hline F- test & & & & & 1.32 & 1.32 & & \\
\hline
\end{tabular}

N.B.

(a) The values of tabulated $t$ and $F$ are (2.31) and (5.14) respectively at $p=0.05$

(b) The values of tabulated $t$ and $F$ are (2.57) and (9.550 respectively at $p=0.05$

\section{Accuracy}

The accuracy of analytical method is defined as the similarity of the results obtained by this method to the true value and the precision as the degree of that similarity [16].

To prove the accuracy of the proposed method, the results were compared with those obtained using the reference method [14]. Moreover, several synthetic mixtures of ROS and GLM in different concentrations were also analyzed. Statistical analysis of the results obtained using Student's t-test and variance ratio F-test [16] revealed no significant difference between the performance of the two methods regarding the accuracy and precision, respectively (Table 2 ).

The proposed procedure offers additional advantages over the reference procedure [14] in that the former is more sensitive with good accuracy and precision. The latter method depends on the analysis of ROS-GLM binary mixture by first derivative spectrophotometric technique up to the concentration of $30 \mu \mathrm{g} / \mathrm{mL}$.

Pharmaceutical application

Dosage form analysis The proposed method was further applied to the determination of the studied drugs in their co-formulated tablets. The results shown in Table 2 are in good agreement with those obtained with the reference method [14]. Statistical analysis of the results obtained using Student's t-test and variance ratio F-test [16] revealed no significant difference between the performance of the two methods regarding the accuracy and precision, respectively (Table 2).

The selectivity of the method was investigated by observing any interference encountered from common tablet excipients such starch, magnesium stearate, lactose and avisil. It was shown that these compounds did not interfere with the results of the proposed method.

\section{Biological application}

The high sensitivity of the proposed method allowed the determination of rosiglitazone in spiked human plasma. The absolute bioavailability of rosiglitazone is 99\%. Following single oral administration of rosiglitazone $8 \mathrm{mg}$ to fasting diabetic patient, a mean peak plasma concentration of $0.117 \mu \mathrm{g} / \mathrm{mL}$ was observed [17]. This concentration lies within the linear concentration range of the proposed method. 

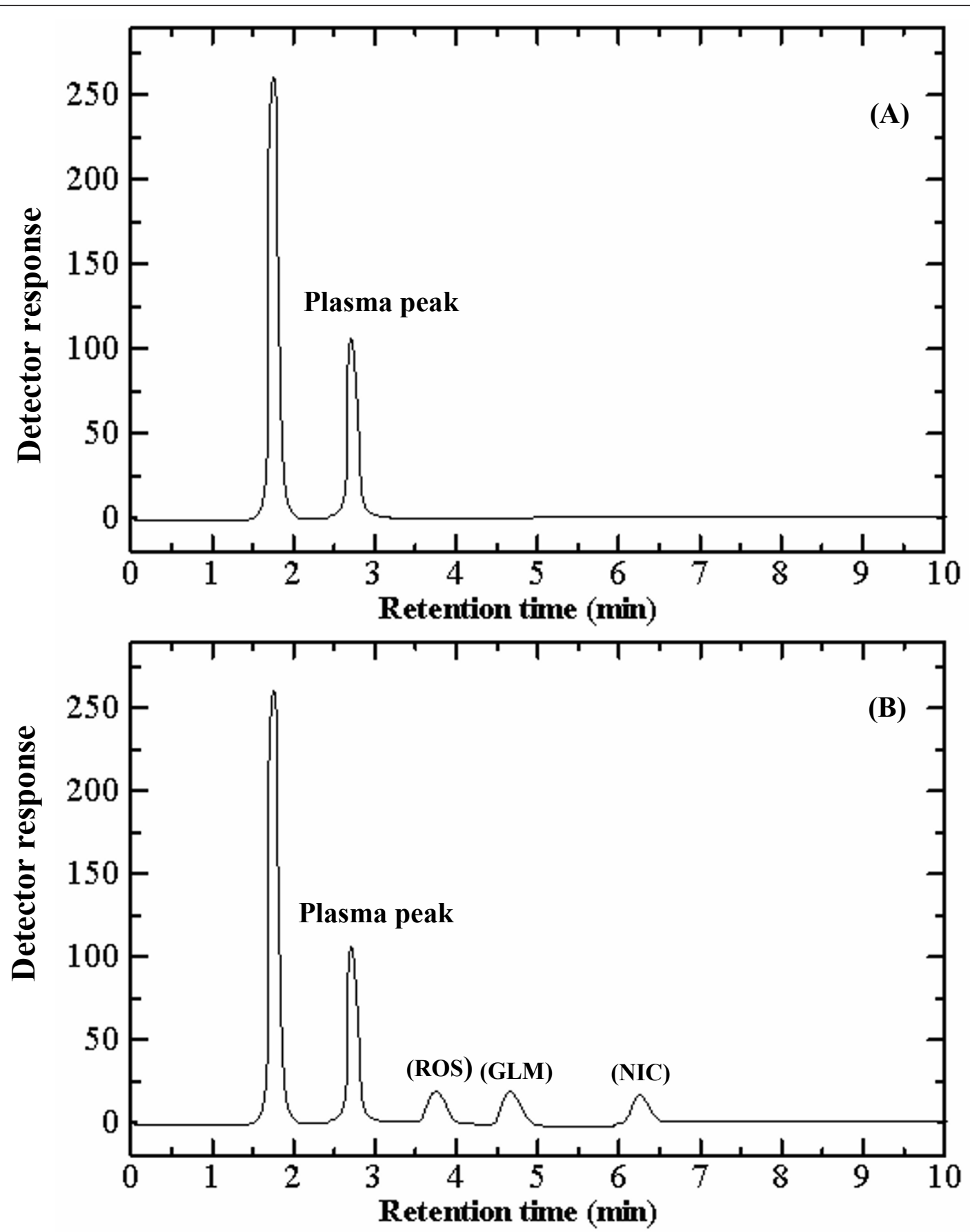

Figure 5 Typical chromatogram for: (A): Blank plasma (B): ROS $\left(1 \mu \mathrm{g} \mathrm{mL}{ }^{-1}\right)$, GLM (1 $\left.\mu \mathrm{g} \mathrm{mL}^{-1}\right)$ and NIC $\left(2 \mu \mathrm{gL} \mathrm{m}^{-1}\right)$ in spiked human plasma.

Following oral administration of a single dose $2 \mathrm{mg}$ of glimipride, a mean plasma level of $0.176 \mu \mathrm{g} / \mathrm{mL}$ was achieved at 2.1 hour [18].

The interference arising from the endogenous amino acids has been overcome by simple precipitation of protein. The method just involved simple plasma protein precipitation with acetonitrile prior to measurement [19].

Figure 5 shows the typical chromatogram of studied drugs obtained from spiked plasma. Table 3 shows the results obtained from spiked plasma. Under the above 
Table 3 Application of the proposed method to the determination of the studied drugs in spiked human plasma.

\begin{tabular}{|c|c|c|c|}
\hline Compound & Concentration taken $(\mu \mathrm{g} / \mathrm{mL})$ & Concentration found $(\mu \mathrm{g} / \mathrm{mL})$ & $\%$ Found \\
\hline \multirow[t]{5}{*}{ Rosiglitazone } & 0.10 & 0.1058 & 105.80 \\
\hline & 0.25 & 0.2398 & 95.92 \\
\hline & 0.50 & 0.5017 & 100.34 \\
\hline & 0.75 & 0.7574 & 100.99 \\
\hline & 1.0 & 0.9964 & 99.64 \\
\hline$x^{\prime}$ & & & 100.54 \\
\hline$\pm \mathrm{SD}$ & & & \pm 3.54 \\
\hline$\%$ RSD & & & 3.52 \\
\hline$\%$ Error & & & 1.57 \\
\hline \multirow[t]{5}{*}{ Glimepiride } & 0.10 & 0.1072 & 107.20 \\
\hline & 0.25 & 0.2487 & 99.48 \\
\hline & 0.50 & 0.4925 & 98.50 \\
\hline & 0.75 & 0.7440 & 99.20 \\
\hline & 1.0 & 1.008 & 100.80 \\
\hline$x^{\prime}$ & & & 101.04 \\
\hline $\pm S D$ & & & \pm 3.55 \\
\hline$\%$ RSD & & & 3.51 \\
\hline$\%$ Error & & & 1.57 \\
\hline
\end{tabular}

described experimental conditions, a linear relationship was established by plotting the peak area ratio against the drug concentration. Linear regression analysis of the data gave the following equations:

$$
\mathrm{PA}=-7.9 \times 10^{-3}+1.142 \mathrm{C} \quad(\mathrm{r}=0.9998)
$$

for ROS,.....

$$
\mathrm{PA}=-0.0197+1.173 \mathrm{C} \quad(\mathrm{r}=0.9998)
$$

for GLM respectively

Where: PA is the peak area ratio, $\mathrm{C}$ is the concentration of the drug in $\mu \mathrm{g} / \mathrm{mL}$ and $\mathrm{r}$ is the correlation coefficient.

The high value of the correlation coefficient $(r)$ indicates the good linearity of the calibration graph.

Precision of the proposed method in spiked human plasma The intra-day precision was evaluated through replicate analysis of plasma samples spiked with different concentrations of ROS and GLM in one day. The mean \%

\begin{tabular}{|c|c|c|c|c|c|c|c|}
\hline \multirow[t]{2}{*}{ Parameters } & & \multicolumn{2}{|c|}{ Concentration added $(\mu \mathrm{g} / \mathrm{mL})$} & \multicolumn{2}{|c|}{ Concentration found $(\mu \mathrm{g} / \mathrm{mL})$} & \multicolumn{2}{|c|}{$\%$ Found } \\
\hline & & ROS & GLM & ROS & GLM & ROS & GLM \\
\hline \multirow[t]{7}{*}{ Intra-day precision } & & 0.5 & 0.5 & 0.4794 & 0.5033 & 95.88 & 100.66 \\
\hline & & 0.75 & 0.75 & 0.7282 & 0.7157 & 97.09 & 95.43 \\
\hline & & 1.0 & 1.0 & 1.0013 & 0.9821 & 100.13 & 98.21 \\
\hline & $(\overline{\mathrm{X}})$ & & & & & 97.70 & 98.10 \\
\hline & \pm S.D. & & & & & 2.19 & 2.62 \\
\hline & $\%$ RSD & & & & & 2.24 & 2.67 \\
\hline & \%Error & & & & & 1.29 & 1.54 \\
\hline \multirow[t]{7}{*}{ Inter-day precision } & $1^{\text {st }}$ day & 0.5 & 0.5 & 0.4769 & 0.459 & 95.38 & 91.80 \\
\hline & $2^{\text {nd }}$ day & 0.75 & 0.75 & 0.7457 & 0.719 & 99.43 & 95.87 \\
\hline & $3^{\text {rd }}$ day & 1.0 & 1.0 & 0.9677 & 0.939 & 96.77 & 93.90 \\
\hline & $(\overline{\mathrm{X}})$ & & & & & 97.19 & 93.86 \\
\hline & \pm S.D. & & & & & 2.05 & 2.04 \\
\hline & $\%$ RSD & & & & & 2.11 & 2.04 \\
\hline & \%Error & & & & & 1.22 & 1.18 \\
\hline
\end{tabular}

Table 4 Validation data for the HPLC analysis of ROS and GLM in spiked human plasma. 
recoveries were $97.70 \pm 2.19$ and $98.10 \pm 2.62$ for ROS and GLM, respectively. Also, the inter-day precision was determined by analyzing the same concentrations over three successive days. The mean percentage recoveries based on the average of three separate determinations were $97.19 \pm 2.05$ and $93.86 \pm 2.04$ for ROS and GLM, respectively. The results are abridged in Table 4 . The small values of \%RSD and \% Error indicates high precision and accuracy of the proposed method and its applicability to human plasma samples.

\section{Co-administered drugs}

Effect of co-administered drugs such as pioglitazone, nateglinide, metformine, glibenclamide and gliclazide was studied. All of the studied drugs interfered with the peak of either ROS or GLM. This necessities developing other separation method.

\section{Conclusion}

The proposed HPLC method is applicable for the simultaneous separation and determination of ROS and GLM in their co-formulated dosage forms. It has distinct advantages over other existing method regarding sensitivity, time saving and minimum detection limits. Moreover, it can be applied to the determination of both drugs in spiked human plasma.

\section{Author details}

'Department of Analytical Chemistry, Faculty of Pharmacy, University of Mansoura, Mansoura, 35516, Egypt. ²Department of Pharmacy, Gifu University Hospital, 1-1 Yanagido, Gifu 501-1194, Japan.

\section{Authors' contributions}

NE designed the proposed method, analysed the data stastistically and wrote the manuscript and collect the literature review. FB proposed, planned and supervised the whole work. AA, YI and MN carried out the experimental work. All the authors read and approved the final manuscript.

\section{Competing interests}

The authors declare that they have no competing interests.

Received: 7 August 2011 Accepted: 26 January 2012

Published: 26 January 2012

\section{References}

1. Balfour JA, Plosker GL: Rosiglitazone. Drugs 1999, 57(6):921-30.

2. AVANDARYL ${ }^{\circledR}$ (rosiglitazone maleate and glimepiride) Tablets. [http:// www.medicineonline.com/drugs/A/4200/AVANDARYL-rosiglitazone-maleateand-glimepiride-Tablets.html].

3. Gomes $\mathrm{P}$, Steppe M: First-derivative spectrophotometry in the analysis of rosiglitazone in coated tablets. J AOAC Int 2006, 89:1296-1299.

4. Walash MI, El-Brashy A, El-Enany N, Kamel ME: Spectrofluorimetric and spectrophotometric determination of rosiglitazone maleate in pharmaceutical preparations and biological fluids. Pharmaceutical Chemistry Journal 2009, 43:697-709.

5. El Sherbiny D, El-Enany N, Belal F: Voltammetric Determination of Rosiglitazone in Pharmaceutical Preparations and Human Plasma. Anal Lett 2008, 41:806-821.

6. Ali AR, Duraidi II, Saket MM, Abu-Nameh ES: Column high-performance liquid chromatographic method for the simultaneous determination of rosiglitazone and metformin in a pharmaceutical preparation. J AOAC Int 2009, 92:119-124.
7. Kang X, Wang F, Xie Z, Li H: A high performance liquid chromatography method for simultaneous determination of rosiglitazone and gemfibrozil in human plasma. J Chromatogr B Analyt Technol Biomed Life Sci 2009, 877:645-648.

8. Yu J, Ma K, Qi J, Jin G, Wang Y, Fang S, Li G: Bioequivalence and comparison of pharmacokinetic properties of 4-mg tablet formulations of rosiglitazone hydrochloride and rosiglitazone maleate: a single-dose randomized, open-label, two-period crossover study in healthy adult male Chinese volunteers. Clin Ther 2008, 30:2272-2279.

9. Altinöz S, Tekeli D: Analysis of glimepiride by using derivative UV spectrophotometric method. J Pharm Biomed Anal 2001, 24:507-515.

10. Ma HL, Xu MT, Qu P, Ma XH: Polarographic behavior and determination of glimepiride. Yao Xue Xue Bao 2005, 40:750-753.

11. A K, G S, C MR, Bhat K, A R, P M, M S, K K, N U: Simultaneous determination of pioglitazone and glimepiride in bulk drug and pharmaceutical dosage form by RP-HPLC method. Pak J Pharm Sci 2008, 21:421-425.

12. Jain $D$, Jain $S$, Jain $D$, Amin M: Simultaneous estimation of metformin hydrochloride, pioglitazone hydrochloride, and glimepiride by RP-HPLC in tablet formulation. J Chromatogr Sci 2008, 46:501-504.

13. Chakradhar L, Kallem R, Karthik A, Sundari BT, Ramesh S, Mullangi $R$, Srinivas NR: A rapid and highly sensitive method for the determination of glimepiride in human plasma by liquid chromatography-electrospray ionization tandem mass spectrometry: application to a pre-clinical pharmacokinetic study. Biomed Chromatogr 2008, 22:58-63.

14. Goyal A, Singhvi I: Simultaneous spectrophotometric estimation of rosiglitazone maleate and glimepiride in tablets dosage forms. Indian Journal Pharm Sci 2007, 69:780-783.

15. ICH Harmonized Tripartite Guideline, Validation of Analytical Procedures Text and Methodology, Q2(R1). , Current Step 4 Version, Parent Guidelines on Methodology Dated November 6 1996, Incorporated in November 2005. [http://www.ich.org/fileadmin/Public_Web_Site/ICH_Products/Guidelines/ Quality/Q2_R1/Step4/Q2_R1_Guideline.pdf](accessed February 15, 2008).

16. Miller JN, Miller JC: Statistics and Chemometrics for Analytical Chemistry. 5 edition. Pearson Education Limited, Harlow, England; 2005, 256.

17. GlaxoSmithKline AV: L19, PRESCRIBING INFORMATION.[http://www.gsk-ecs. com/news/private/Avandia AV L19 P.I.pdf], (accessed March, 2007).

18. Moffat AC, Osselton MD, Widdop B: Clark's Analysis of Drugs and Poisons in Pharmaceuticals, Body fluids and Postmortem Material. The Pharmaceutical Press, London; 3 2004, 1081.

19. Hruska MW, Frye RF: Simplified method for determination of rosiglitazone in human plasma. J Chromatogr B Analyt Technol Biomed Life Sci 2004, 803:317-320.

doi:10.1186/1752-153X-6-9

Cite this article as: El-Enany et al:: Development and validation of a repharsed phase- HPLC method for simultaneous determination of rosiglitazone and glimepiride in combined dosage forms and human plasma. Chemistry Central Journal 2012 6:9.

\section{Publish with ChemistryCentral and every scientist can read your work free of charge \\ "Open access provides opportunities to our colleagues in other parts of the globe, by allowing anyone to view the content free of charge." W. Jeffery Hurst, The Hershey Company.}

- available free of charge to the entire scientific community

- peer reviewed and published immediately upon acceptance

- cited in PubMed and archived on PubMed Central

- yours - you keep the copyright

Submit your manuscript here:

http://www.chemistrycentral.com/manuscript/<smiles>c1ccccc1</smiles>

ChemistryCentral 